\title{
Influências dominantes na construção da prática pedagógica de uma aluna- professora de Língua Inglesa
}

Suely Ana Ribeiro

Universidade Federal de Goiás ${ }^{1}$

\begin{abstract}
Nos últimos anos, os pesquisadores têm mostrado um crescente interesse pela natureza do trabalho docente e sobre os tipos de saberes que os professores evocam nos eventos de ensino. Este artigo trata de questões sobre as diversas experiências de formação que o professor vivencia ao longo dos anos. Por meio da reflexão guiada por três das quatro perguntas pedagógicas de Smyth (1992), uma aluna-professora do quinto ano de Letras revelou a força que algumas de suas experiências de formação têm exercido em sua prática de ensino. Tais experiências foram categorizadas com base em Tardif (1999) e Bailey et al. (1996). Os resultados deste estudo nos fazem refletir sobre a nossa própria prática de ensino de língua inglesa.

In the last years there has been a growing interest in research about the nature of teachers' practice and about what kind of knowledge they evoke in their teaching events. This paper deals with issues concerning teacher education experiences. By reflecting and answering three out of Smyth's (1992) four pedagogical questions, one $5^{\text {th }}$ year student-teacher revealed the power some of her education experiences have had in her teaching practice. These experiences were categorized based on Tardif (1999) and Bailey et al. (1996). The results of this study make us reflect about our own English teaching practice.
\end{abstract}

\section{Introdução}

Tem havido nos últimos anos um crescente interesse por pesquisas que buscam compreender a natureza do trabalho docente, quais são seus propósitos, seus processos, seus resultados e quais tipos de saberes o profissional do ensino evoca em sua tarefa de ensinar (LITTLE; MCLAUGHLIN, 1993; NÓVOA, 1995; GERALDI et al., 1998; TARDIF, 1999).

${ }^{1}$ Mestranda do curso de Lingüística da Universidade Federal de Goiás - UFG 
Parece-nos óbvio que os professores fundamentam seu fazer pedagógico nos saberes adquiridos nos cursos de formação inicial. Essa seria a conclusão lógica, uma vez que dedicam quatro ou cinco anos de suas vidas aos seus cursos de licenciatura, certos de que tais cursos possam provê-los dos conhecimentos sobre as disciplinas que pretendem ensinar, bem como sobre a maneira de ensinar esses mesmos conteúdos aos seus alunos.

O exercício profissional, contudo, nos mostra que essa relação curso de formação inicial X atuação pedagógica não ocorre de forma tão tranqüila e direta assim. Na verdade, os professores mobilizam em suas ações pedagógicas, além dos conhecimentos adquiridos na universidade, um vasto conjunto de saberes adquiridos ao longo de suas vidas. Segundo Tardif (1999), "não se deve confundir os saberes profissionais com os conhecimentos adquiridos no âmbito da formação universitária". O autor chama a atenção para o fato de que embora o conhecimento adquirido no curso de formação inicial seja reconhecidamente importante para o exercício docente, ele não abrange todos os tipos de saberes que um professor precisará mobilizar nas diversas situações de ensino com as quais terá de lidar no exercício de sua profissão. Além disso, é necessário observar que cada professor recebe os conhecimentos adquiridos na formação inicial e os metaboliza de acordo com outros tipos de saberes que possui, como experiências de vida, crenças e valores. Assim, não há dois profissionais que possuam exatamente os mesmos saberes, assim como não há dois eventos de ensino iguais. Tardif (1999) destaca que os saberes profissionais dos professores são personalizados, difíceis de dissociar da pessoa, de suas experiências e de seus contextos particulares de trabalho.

Assim, com base na concepção de Tardif sobre a constituição dos saberes profissionais, me propus a investigar que experiências de formação têm exercido influência sobre a prática pedagógica de uma professora de língua inglesa, aluna do $5^{\circ}$ ano do curso de Letras de uma universidade pública de Goiânia. Busquei, também, verificar em que medida os saberes adquiridos no curso de formação inicial, especialmente na disciplina de Didática e Prática de Ensino da Língua Inglesa, têm sido materializados na prática docente da professorasujeito. Para desenvolver esta investigação, orientei-me pelas seguintes perguntas de pesquisa: 
1. Que tipos de experiências de formação exercem influência sobre a atuação pedagógica da professora-sujeito?

2. Os saberes adquiridos na disciplina de Didática e Prática de Ensino de Língua Inglesa são transpostos pela professora para as situações de ensino em sala de aula?

3. Há predominância de algum tipo de experiência de formação sobre os outros tipos?

A pesquisa proposta justifica-se pela contribuição que pode prestar à professora-sujeito por meio da reflexão que ela, inevitavelmente, fez a respeito de sua prática docente, bem como a todos os profissionais do ensino de língua inglesa que, ao tomarem contato com a pesquisa, terão a oportunidade de refletir sobre a sua prática, seja ela como docente de língua inglesa nos níveis básicos de ensino ou como professor formador nas instituições de ensino superior.

\section{Organização do artigo}

O presente artigo está organizado em oito partes precedidas pela introdução, que contextualiza a investigação e apresenta seus objetivos, suas justificativas e as perguntas que nortearam seu desenvolvimento.

A primeira parte apresenta brevemente o conceito de formação e as implicações que traz para o desenvolvimento do profissional do ensino. A segunda parte traz os modelos de formação de Wallace (1995) e situa qual desses modelos apresenta características que podem atender às necessidades do contexto atual de ensino no Brasil. Em seguida, são brevemente expostas as seis estratégias de reflexão/formação propostas por Amaral et al. (1996). A quarta seção trata especificamente das perguntas pedagógicas de Smyth, uma vez que foram utilizadas para o desenvolvimento da pesquisa. A quinta seção descreve a professorasujeito desta pesquisa, os instrumentos utilizados para a coleta de dados e os procedimentos de análise. A sexta parte esclarece como os dados foram categorizados. A sétima parte traz a análise dos dados, enquanto a última apresenta as considerações finais deste estudo.

Comecemos por definir o que se entende por formação nesta investigação. 


\section{Mas o que é formação?}

Leffa (2001) conceitua a formação em oposição ao treinamento. Segundo o autor, treinar professores implica ensinar-lhes técnicas de ensino, sem construir uma base teórica, visando a resultados imediatos em sala de aula. Por outro lado, formar o professor implica a busca da reflexão e das razões por que uma ação é realizada da maneira como é realizada. A formação pressupõe embasamento teórico, pressupõe um diálogo entre teoria e prática. Assim, o treinamento atende às necessidades momentâneas, enquanto a formação tem o olhar voltado para o futuro e entende o desenvolvimento profissional como um processo contínuo. Ressalte-se que o treinamento pode constituir parte da formação profissional. Não pode, contudo, ser tratado como a formação, de fato.

Medina e Domingues (apud Garcia, 1999) acrescentam à formação a função de desenvolver no professor um estilo crítico e reflexivo de ensinar, um estilo que o torne capaz de avaliar continuamente sua prática pedagógica e os resultados que ela produz. Além disso, espera-se que esse professor seja capaz de operar mudanças no processo de ensino sempre que necessário, a fim de promover uma aprendizagem significativa, uma aprendizagem que constitua resposta para os questionamentos, interesses e necessidades reais do aluno.

Dessa forma, não se pode mais pensar num profissional do ensino treinado apenas para seguir "receitas". A sociedade é dinâmica, evolui continuamente. O professor precisa, então, acompanhar a dinâmica da sociedade e manter-se em formação contínua.

A seção seguinte apresenta os modelos de formação de Wallace (1995).

\section{Os modelos de formação de professores}

Os modelos de formação profissional têm sofrido modificações ao longo dos anos, pois cada sociedade, cada momento histórico demanda um profissional com perfil diferente.

Há, historicamente, segundo Wallace (1995), três grandes modelos de formação do profissional do ensino: o modelo da maestria, o modelo da ciência aplicada e o modelo reflexivo. 
O modelo da maestria considera que a sabedoria do profissional reside na experiência profissional acumulada: o aluno-professor aprende imitando um professor mais experiente, que ensina aos alunos o que e como fazer. Tal modelo prevê uma sociedade estática, imutável, o que não condiz com a realidade.

O modelo da ciência aplicada prevê que o conhecimento científico seja transmitido aos alunos-professores pelos especialistas. Os alunos colocam esse conhecimento em prática e, assim, atingem a competência profissional. Esse modelo, no entanto, desconsidera a imprevisibilidade das situações com que um professor pode se deparar no exercício da prática docente.

O terceiro modelo de formação profissional, o modelo reflexivo, leva em conta o conhecimento recebido, o conhecimento experiencial, a prática, a reflexão e a competência profissional. Para Wallace (1995), entre prática e reflexão deve haver um movimento cíclico, uma alimentando a outra, a fim de alcançar a "competência profissional", entendida pelo autor como um conceito dinâmico, um ponto que nunca é totalmente atingido, pois há sempre algo novo a desenvolver. Segundo Amaral et al. (1996), o modelo reflexivo permite um diálogo entre prática e teoria, levando o profissional à construção e à reconstrução de seus conhecimentos.

O contexto atual do ensino demanda um profissional reflexivo, um profissional que esteja sempre irrequieto, em busca do desenvolvimento de suas potencialidades e da superação das dificuldades que eventualmente surjam em sua trajetória, um profissional capaz de tomar decisões diante dos imprevistos próprios das profissões em que o contato com pessoas é estabelecido, decisões essas baseadas em seus diferentes tipos de saberes, considerando experiências pessoais, valores e anseios dos alunos, pois educação envolve seres humanos com emoções, com sentimentos, com experiências que são sempre únicas.

Na próxima seção serão apresentadas as estratégias de reflexão/ formação de professores apontadas por Amaral et al. (1996, p. 100) como meios para formar "professores que examinam, questionam e avaliam criticamente a sua prática". 


\section{As estratégias de reflexão/formação de professores}

Considerando a importância da reflexão para a formação do professor, Amaral et al. (1996) apresentam algumas estratégias de formação de professores que constituem meios de desenvolver a prática da reflexão já nos cursos de formação inicial. Sabe-se, contudo, que a prática reflexiva é um aprendizado árduo. Tavares e Alarcão (1992) chamam a atenção para a necessidade de considerarem-se os diferentes estágios de desenvolvimento do profissional para apresentarem-se as diferentes estratégias de reflexão/formação, pois há entre elas uma relação estruturante, articuladora e de interdependência.

Amaral et al. (1996) apresentam, então, as seguintes estratégias para a formação do professor reflexivo: as narrativas, a análise de casos, a observação de aulas, o trabalho com projetos, a investigação-ação e as perguntas pedagógicas.

As narrativas prevêem relatos de práticas pedagógicas. Ao fazêlas, o professor terá a oportunidade de desenvolver sua sensibilidade e sua capacidade de observação das situações de ensino. Na análise de casos são registrados acontecimentos problemáticos da sala de aula, os quais são interpretados e explicados à luz de conhecimentos teóricos, promovendo, assim, uma reflexão sobre a ação. A observação de aula, por sua vez, promoverá, entre outros benefícios, a aproximação do aluno-professor da realidade de ensino e o desenvolvimento de uma postura investigativa em relação à prática pedagógica. Já o trabalho com projetos, geralmente promove o estudo de problemas considerados de interesse por um grupo de profissionais que desenvolve um esforço conjunto para resolvê-lo, e a investigação-ação surge da necessidade de melhorar uma dada situação. Parte-se, então, para o planejamento de uma ação, a implementação do plano elaborado, a observação dos efeitos da ação e a reflexão sobre os efeitos observados. Essa reflexão pode gerar a elaboração de um novo plano, iniciando, assim, um novo ciclo reflexivo.

Por fim, apresentarei, na próxima sessão, as perguntas pedagógicas de Smyth (1992), uma vez que essa foi a estratégia eleita por mim para o desenvolvimento da pesquisa. 


\section{As perguntas pedagógicas}

Segundo Smyth (1989), a reflexão pode - e deve - começar na própria sala de aula do professor. Não deve, contudo, restringir-se a ela. É desejável que a reflexão atinja um nível que alcance os princípios éticos e políticos que permeiam o ensino e as relações deste com as hierarquias da sociedade. Vale ressaltar que a prática da reflexão não é um simples exercício de pensamento mas, sim, uma prática que deve ser desenvolvida gradativamente, assumindo, aos poucos, níveis mais complexos.

Smyth (1992) sugere que pesquisadores desenvolvam com os professores-participantes de suas pesquisas interações que os conduzam em um processo reflexivo, com base em quatro perguntas: 1) Descrever: O que eu faço?; 2) Informar: O que isso significa?; 3) Confrontar: Como eu me tornei assim?; e 4) Reconstruir: Como eu poderia agir diferentemente?

As quatro perguntas pedagógicas de Smyth (1992) constituem um roteiro para orientar a reflexão do professor e devem contribuir "no sentido de mudar as condições de ensino, descobrindo a natureza das forças que inibem e restringem a ação dos professores" (AMARAL et al., 1996, p. 103).

O primeiro nível de reflexão busca resposta para a primeira pergunta pedagógica - O que eu faço? - e deve promover uma reorganização das experiências de ensino e a descrição das práticas pedagógicas do professor.

A segunda pergunta pedagógica - O que isso significa? - deve levar o professor à interpretação das suas ações pedagógicas e à compreensão das ações que realiza em sala de aula. Busca-se, nesse nível, o desvelar dos princípios e teorias que subjazem a prática do professor.

A terceira pergunta pedagógica - Como me tornei assim? - deve guiar o professor em reflexões que o levem a questionar sua ação pedagógica como fruto de forças sociais e culturais e o torne consciente das múltiplas forças que o levaram a tornar-se o profissional que é.

Enfim, o último nível de reflexão busca responder à quarta pergunta: Como poderei me modificar? Ao alcançar esse nível de reflexão o professor estará em condições de reconstruir suas crenças e modificar suas práticas, consciente de que "ensino não é uma realidade imutável, definida por outros, mas contestável na sua essência” (AMARAL et al., p. 103). 
A prática reflexiva exercida com base nas quatro perguntas pedagógicas de Smyth (1992) conferirá ao professor uma autonomia que o tornará capaz de decidir o que é melhor para a sua atuação docente, considerando todas as variáveis que nela interferem, como contexto, idade e interesses dos aprendizes, o papel que assume diante do grupo, entre outros.

Neste estudo as perguntas pedagógicas de Smyth (1992) foram utilizadas como guias para direcionar a reflexão da professora-sujeito e para que ela pudesse resgatar as diversas experiências que contribuíram para que se constituísse a profissional que é hoje.

Faz-se necessário destacar que apenas as três primeiras perguntas foram utilizadas, pois alcançar o quarto nível de reflexão demandaria um maior tempo de pesquisa e coleta de dados.

\section{A professora-sujeito e a metodologia da pesquisa}

Virgínia ${ }^{2}$ é aluna do quinto ano do curso de Letras de uma universidade pública de Goiânia. Atua no ensino de língua inglesa há oito anos, em cursos livres e no Centro de Línguas da universidade onde estuda há dois anos. Morou durante um ano num país de língua inglesa e lá cursou o último ano do ensino médio.

Os dados para esta pesquisa foram coletados por meio de questionário, entrevista semi-estruturada e observação de aula. O questionário objetivou promover uma reflexão guiada pelas três primeiras perguntas pedagógicas de Smyth (1992). Por meio da observação, buscou-se verificar se as práticas exercidas pela professora-sujeito em sala de aula estão em consonância com seus relatos do questionário e da entrevista, bem como que tipos de experiências de formação se materializam em sua atuação. Na entrevista semi-estruturada, gravada em áudio, buscou-se, por fim, elucidar possíveis dúvidas sobre as práticas pedagógicas que a professora realiza em sala de aula e sobre as diversas experiências de formação que influenciam sua prática.

\footnotetext{
${ }^{2}$ Virgínia é o nome fictício adotado pela professora-sujeito desta investigação.
} 
A presente pesquisa tem caráter qualitativo, modelo apropriado quando o fenômeno em estudo é complexo, de natureza social e não tende à quantificação. Insere-se, ainda, no modelo interpretativista, uma vez que busca compreender um fenômeno a partir dos próprios dados e das referências fornecidas pelos sujeitos estudados e dos significados atribuídos ao fenômeno pelos participantes (NUNAN, 1992).

\section{A categorização das experiências de formação}

Tardif (1999, p. 15) chama de epistemologia da prática profissional "o estudo do conjunto dos saberes utilizados realmente pelos profissionais em seu espaço de trabalho cotidiano para desempenhar todas as suas tarefas". A epistemologia da prática profissional revela quais saberes são mobilizados no ato pedagógico e como eles são incorporados, produzidos e utilizados pelos profissionais do ensino em suas atividades docentes. Tardif (1999, p. 17) acrescenta, também, que "a prática profissional nunca é o espaço de aplicação dos conhecimentos universitários". Será, no máximo, o espaço de filtragem e transformação desses saberes em função de atender às exigências reais do trabalho.

Os dados coletados neste estudo apontam para experiências de formação que podem ser categorizadas de acordo com Tardif (1999, p. 21), para quem os saberes dos professores provêm de diversas fontes. Segundo o autor, no exercício profissional, um professor se serve de "sua cultura pessoal", "de sua história de vida" e sobretudo "da sua história de vida escolar", uma vez que é um trabalhador que esteve imerso em seu universo de trabalho, mesmo que na condição de aluno, durante longos anos. Tardif $(1999$, p. 21) complementa que o professor apóia-se, também, "em certos conhecimentos disciplinares adquiridos na universidade", "em certos conhecimentos didáticos e pedagógicos oriundos de sua formação profissional", "nos conhecimentos curriculares veiculados pelos programas, guias e manuais escolares", "em seu próprio saber ligado à experiência de trabalho", "na experiência de outros professores e em tradições peculiares ao ofício de professor". O autor acrescenta que "ainda hoje, a maioria dos professores aprende, a trabalhar na prática, às apalpadelas, por tentativa e erro" (p. 20).

Bailey et al. (1996) corroboram Tardif (1999) no que se refere à experiência de formação adquirida por meio da experiência como 
aprendiz. Segundo os autores, os professores ficam expostos ao ensino por muito tempo e internalizam muitos dos comportamentos de seus professores, sejam eles bons ou maus modelos (BAILEY et al., 1996).

Assim, as experiências de formação da professora-sujeito dessa pesquisa serão categorizadas, com base em Tardif (1999) e Bailey et al. (1996), de cinco maneiras, a saber:

1. Experiência como aprendiz (BAILEY, 1996; TARDIF, 1999);

2. Experiência como professor (TARDIF, 1999);

3. Experiência no contato com outros professores (TARDIF, 1999);

4. Experiência em cursos de formação (TARDIF, 1999);

5. Experiência por meio de leituras (TARDIF, 1999).

Apresentadas as cinco categorias de experiências de formação de professor para as quais os dados deste estudo apontaram, passo, na sessão seguinte, à analise desses dados.

\section{Análise dos dados}

Para a análise dos dados foram utilizados recortes do questionário (Q) e da entrevista (E), nos quais a professora-sujeito tenha feito referência a algum dos tipos de experiência de formação categorizados de acordo com Bailey (1996) e Tardif (1999), e os dados coletados por meio da observação da aula. Esses recortes foram classificados de acordo com as cinco categorias já apresentadas.

Por uma questão de organização, todos os recortes referentes a um mesmo tipo de experiência de formação serão apresentados em seqüência. Assim, a análise se dará na seguinte ordem: a) experiência como aprendiz; b) experiência em curso de formação; c) experiência de leitura; d) experiência como professor; e e) experiência no contato com outros professores.

A experiência como aprendiz de língua inglesa foi mencionada várias vezes tanto no questionário quanto na entrevista. Virgínia relatou, por exemplo, que no ensino fundamental "gostava muito de estudar 
porque tinha a prática oral da lingua" (E). No questionário, também ressalta a força da prática oral em sua experiência como aprendiz da seguinte forma:

Privilegio a prática de atividades orais e de compreensão auditiva em sala, já que as outras podem ser realizadas individualmente em casa e, posteriormente, aprimoradas em sala (Q).

A observação da aula permitiu confirmar a atenção especial dispensada à prática oral. A professora incentivou bastante a expressão oral, oportunizando a todos os alunos a participação. Na aula observada, houve uma discussão sobre estratégias ${ }^{3}$ para manter o emprego e os interesses que se ocultavam por trás daquelas estratégias. A prática oral fluiu bem e os alunos não demonstraram constrangimentos para falar.

Outra experiência de aprendiz que Virgínia trouxe para sua prática foi a revisão da produção escrita pelos pares. A aluna-professora foi convicta quando disse: "Eu acredito que quanto mais o aluno tiver a sua produção revisada, não só por mim mas também por outros alunos, ele vai estar tendo feedback da produção dele [...] Foi assim que aconteceu comigo..." (E).

Em outro momento da entrevista, ela fala sobre sua experiência de aprendiz de língua inglesa já no curso de Letras e reforça sua experiência positiva com a prática da produção escrita revisada. Virgínia afirma que

Realmente a professora corrigia e devolvia (as redações). Ela não só analisava o conteúdo como também a forma e aí, sim, que eu vi realmente algum progresso na escrita em inglês [...] A última redação eu refiz seis vezes (E).

$\mathrm{Na}$ aula observada, após desenvolver a prática oral, Virgínia solicitou aos alunos que, em pares, revisassem as produções escritas um do outro. A aluna-professora orientou-os para que fossem muito atenciosos na correção e discutissem possibilidades de melhorar os textos. Em casa, deveriam reescrevê-los e entregá-los na seguinte aula. Dessa forma, mais uma experiência como aprendiz se materializa na prática da professora.

${ }^{3}$ Essas estratégias para manter o emprego sugeriam, de modo subliminar, que o funcionário deveria colocar a empresa acima de todos os seus demais interesses. Eram estratégias que traduziam a ótica do patrão. 
Virgínia traz ainda, para sua sala de aula, mais uma de suas experiências como aprendiz. A aluna-professora, ao relatar sobre sua experiência morando em um país de língua inglesa, afirma que aprender a lingua relacionada a algum interesse pessoal como culinária ou artes ou, ainda, motivada por uma necessidade real como escrever um bilhete, atribui significado à aprendizagem e os resultados, conseqüentemente, serão melhores. A esse respeito, ela se pronuncia assim:

Eu tinha que aprender as funções da língua pra poder realmente estar usando aquelas funções no meu dia-a-dia: para pedir alguma coisa, para informar, para deixar algum bilhete pra o pessoal da minha casa. [...] Estudei matérias do meu interesse como culinária, teatro, artes... (E).

A respeito das práticas que desenvolve em sala de aula, Virgínia relata no questionário:

Eu procuro desenvolver as quatro habilidades da forma mais natural possível [...] envolvo o novo tópico com algo bem corriqueiro e próximo da realidade vivenciada pelos alunos, de forma que eles se identifiquem com o que foi introduzido quase que instantaneamente (Q).

É possível perceber um esforço de Virgínia para promover situações de aprendizagem mais próximas da realidade dos alunos. Esse esforço se justifica pela sua experiência de aprendiz de língua inglesa (no exterior), pois se sentia muito mais motivada a aprender quando a aula estava relacionada a algum assunto de seu interesse, como culinária, artes ou esportes radicais.

A aula observada mostrou a preocupação que a professora tem em promover a aprendizagem da língua em situações relacionadas à vida dos alunos. Virgínia problematizou com os alunos as questões que envolvem a manutenção de um emprego e perguntou se eles se submeteriam a colocar as estratégias sugeridas no texto em prática. Além disso, questionou-os sobre os interesses que se ocultavam naquelas estratégias e a quem elas beneficiariam. A professora abriu espaço para que os alunos relatassem experiências relacionadas ao tema.

Vale ressaltar que a turma em que as estratégias para manter o emprego foram discutidas cursa o sétimo semestre de um curso de oito semestres e é formada por alunos com idades variando entre 18 e 50 anos. A conversa sobre o tema é, então, bastante relacionada à vida deles. 
Os recortes apresentados nos permitem perceber a força da experiência como aprendiz no fazer pedagógico de Virgínia.

Os dados apontam, também, para as experiências de formação adquiridas em curso de formação. Virgínia, ao responder como encaminha suas aulas, afirma: "Eu estruturo minhas aulas em três estágios básicos: apresentação, prática e produção" (Q). Na entrevista ela acrescenta: "depois de ter feito o treinamento (para atuar no Centro de Línguas) no $1^{\circ}$ ano, eu assisti novamente quando eu estava no $2^{\circ}$ ano porque eu queria estar realmente me aprofundando nisso" (E).

Ao estruturar suas aulas de acordo com os três estágios básicos, a professora transpõe para a sua prática saberes desenvolvidos em cursos de formação, neste caso o treinamento feito no Centro de Línguas. Ela acrescenta que o curso supria o seu interesse em "estar melhorando as [...] aulas, estar tendo mais conhecimento sobre os métodos, sobre atividades para fazer em sala de aula" (E).

Ao ser questionada sobre sua experiência no curso de Didática e Prática de Ensino de Língua Inglesa, Virgínia relata com entusiasmo:

Ah, está sendo maravilhoso! Eu entrei aqui [...] pensando que ia ter essa matéria no primeiro ano porque eu já dava aula e eu queria estruturar certinho na minha cabeça o que é dar as aulas, como eu posso dar as aulas, quais são as opções de atividades que eu posso fazer (E).

Virgínia ainda está cursando a disciplina de Didática, mas a contribuição dessa experiência para a formação da professora parece clara em sua atuação em sala de aula. Embora na observação de aula não tenha sido possível verificar os estágios básicos mencionados pela professora, pois a aula não foi de apresentação de conteúdo, foi possível observar uma aula bem estruturada, centrada na habilidade oral, com atividades diversificadas, como análise e debate sobre o texto, discussão em pares e apresentação do resultado da discussão para a classe toda, além da revisão colaborativa de textos. Entende-se que a estruturação da aula, a habilidade de gerenciá-la de maneira descontraída, o pronto esclarecimento das dúvidas dos aprendizes, a boa utilização do tempo, o tratamento dispensado aos alunos e o tratamento aplicado nos momentos em que houve erro são procedimentos didáticos fundamentados nos saberes desenvolvidos no curso de treinamento, no curso de Didática e Prática de Ensino de Língua Inglesa ou no curso de formação inicial de modo geral. 
Outra experiência de formação mencionada pela aluna-professora foi a adquirida por meio de leituras. Virgínia fez uma única menção a esse tipo de experiência, o que sugere que, talvez, as leituras não têm exercido uma influência marcante em sua formação. Acerca dessa experiência, a professora assim se expressou:

Antes disso eu já tinha começado a dar aula, então a minha leitura era manual de professor de inglês, os livros didáticos, a gramática e alguns livros que eu tinha [...] para poder trabalhar, melhorar o vocabulário em inglês. [...] Depois que eu fiz o treinamento a gente viu alguns textos teóricos (E).

Com relação à observação da aula, não foi possível estabelecer uma relação direta entre uma experiência de leitura e a prática desenvolvida em sala de aula. Contudo, é inegável que a leitura, seja de manuais, de livros didáticos, de gramáticas ou de textos teóricos, exerce influência sobre o fazer pedagógico da professora, que filtra esses saberes e os reconstrói, mesclando-os com outros saberes que possui. O resultado dessa filtragem é materializado na prática da professora.

A experiência como professora é, também, mencionada por Virgínia. Segundo ela, no início de sua atuação como professora, "era muito preocupada com a forma. Meus alunos tinham que produzir 100\% correto ou não produzir" (E). Os anos de experiência mostraram à professora a necessidade de focalizar mais o conteúdo do que a forma na produção do aluno. A esse respeito, ela afirma:

[...] mas eu não vou parar a pessoa de falar pra eu poder corrigir a forma. Eu tenho que prestar atenção no conteúdo e posteriormente corrigir a forma, se pintar uma situação (E).

Virgínia reconhece a importância da experiência que adquiriu como professora para o seu desenvolvimento profissional. A alunaprofessora, em resposta à questão sobre como se tornou a profissional que é, afirma: "[...] eu me tornei a professora que eu sou hoje graças [...] às oportunidades de emprego que surgiram e, conseqüentemente, à necessidade de aperfeiçoamento na área; a todo meu estudo formal e informal feito até hoje..." (Q).

A observação da aula nos permitiu confirmar a atitude da professora diante das situações de fala em que os alunos cometem erros. Como relatado por ela na entrevista, não houve interrupção para 
correções durante o momento da fala, apenas posteriormente. Isso parece confirmar a importância da experiência adquirida ao longo dos anos de experiência profissional como uma experiência de formação do professor, visto que houve superação da prática de correção excessiva da forma relatada pela professora na entrevista.

Por fim, Virgínia aponta, ainda, a experiência de formação adquirida no contato com outros professores. Tal experiência foi mencionada apenas na entrevista, porém, em vários momentos. Virgínia relata, por exemplo, mudanças em seu modelo de prova realizadas depois de assistir a uma defesa de dissertação de mestrado a respeito do tema. A esse respeito ela afirma:

Até hoje eu me lembro que eu mudei completamente o meu modelo de prova depois da apresentação do trabalho de uma aluna que tinha defendido o mestrado falando que os professores davam aulas comunicativas, mas as provas eram centradas em tópicos gramaticais, em detalhes da forma da língua e não prestavam atenção ao conteúdo (E).

A aluna-professora complementa que a sala dos professores é espaço "para a resolução de todos os problemas, não só didáticos e pedagógicos como financeiros [...] é um tal de trocar xerox, trocar atividades, o que você fez para ensinar isso e tal, mas é sempre na informalidade" (E).

Virgínia relata, também, a experiência com sua supervisora no Centro de Línguas, com quem tem encontros semanais. Segundo ela, esses encontros são voltados "para as aulas em específico: eu mostro os quatro planos, ela me sugere alguma prática e eu vou e dou minhas aulas".

Embora a professora reconheça a importância dessas experiências para sua atuação em sala de aula, não foi possível estabelecer relações entre os dados da entrevista e a aula observada. Ressalta-se, contudo, que apenas uma aula foi observada, o que constitui um recorte muito pequeno da prática da professora.

Assim, a discussão dos dados do questionário, da entrevista e da observação de aula constitui resposta para a primeira pergunta de pesquisa, apontando que tipos de experiências de formação têm servido como base para a prática pedagógica de Virgínia.

Passemos a responder à segunda pergunta, sobre a transposição dos saberes desenvolvidos na disciplina de Didática e Prática de Ensino de Língua Inglesa para a sala de aula. 
Virgínia expressa sua expectativa com relação ao curso de Didática e Prática de Ensino de Língua Inglesa desde o início do curso - "Eu entrei aqui pensando que eu ia ter essa matéria no primeiro ano" - e faz referência ao curso, cujas aulas estão acontecendo só no quinto ano, com entusiasmo - "Ah! Está sendo maravilhoso!". Além disso, a professorasujeito dispõe de conhecimentos sobre metodologias de ensino, papel do professor em sala de aula, tratamento de erros, correção e revisão da produção escrita, adquiridos ou lapidados nesse curso. Os saberes adquiridos na disciplina de Didática e Prática de Ensino de Língua Inglesa são claramente observáveis na aula da professora-sujeito, portanto, há transposição dos conhecimentos desenvolvidos nessa disciplina para os eventos de ensino em sala de aula.

Com relação à última pergunta, foi possível observar que não há predominância de um tipo de experiência sobre as outras. Virgínia demonstrou que sua prática docente é fortemente influenciada por quatro dos cinco tipos de experiências de formação categorizados neste estudo, a saber: a experiência como aprendiz, a experiência vivenciada nos cursos de formação, a experiência como professora e a experiência adquirida no contato com outros professores. Dentre esses quatro tipos, talvez a experiência como aprendiz se sobressaia sutilmente em relação às demais, mas não o suficiente para quebrar o equilíbrio entre os quatro tipos. O quinto tipo de experiência de formação, aquele adquirido por meio de leituras, de acordo com os dados coletados, parece exercer uma influência menor sobre a aluna-professora.

Respondidas as três perguntas de pesquisa, a última seção traz as considerações finais deste estudo.

\section{Considerações finais}

A análise dos dados coletados nesta pesquisa nos levou a algumas constatações.

A primeira constatação é que a professora-sujeito desta pesquisa tem pautado sua prática pedagógica por diversos tipos de experiências de formação de maneira equilibrada, ou seja, ela extrai de cada uma de suas experiências de formação o que tal experiência puder oferecer de positivo. Isso também se deve ao fato de a professora mostrar-se uma pessoa muito comunicativa e aberta ao aprendizado. 
A segunda constatação está relacionada às marcas da experiência como aprendiz de língua inglesa na prática de Virgínia. A professorasujeito cita, de maneira bastante enfática, várias de suas experiências como aprendiz que ela traz para a sala de aula e desenvolve com seus alunos. As experiências malsucedidas também servem como modelo para não seguir. Na verdade, a forte influência da experiência como aprendiz não deve surpreender, se considerarmos o tempo que todos passamos expostos a situações de aprendizagem na condição de aprendizes. Esse tipo de experiência é indissociável do profissional do ensino, embora haja uma variação na intensidade com que essas experiências são evocadas.

Este estudo mostrou, ainda, que o curso de Didática e Prática de Ensino de Língua Inglesa tem exercido uma influência decisiva no fazer pedagógico da professora, que tem materializado em suas aulas os saberes desenvolvidos neste curso. A constatação de que a informante da pesquisa tem exercido uma prática orientada pelas reflexões, teorias e práticas apresentadas e discutidas no curso de Didática é animadora e aponta para este curso como um espaço essencial de construção de saberes, troca de idéias, estudo de teorias, análise e reflexão coletivas sobre assuntos relacionados ao ensino de língua inglesa.

Somada às constatações anteriores, a força da cooperação entre os colegas professores por meio da troca de idéias e de materiais, discutindo e refletindo sobre os eventos de ensino mostra-se, também, como uma boa perspectiva, pois fortalece a classe, melhora a prática pedagógica do professor e promove a difusão de estratégias de desenvolvimento e formação profissional.

A última constatação é a de que a experiência de formação que exerce menos influência na atuação pedagógica da professora-sujeito é aquela adquirida por meio de leituras. Tal constatação em princípio choca, uma vez que a leitura seria uma atividade inerente à profissão. Contudo, é sempre positivo ter consciência de um problema para poder tomar medidas para erradicá-lo ao invés de mantê-lo velado.

Por fim, espera-se que os resultados dessa pesquisa possam servir para que possamos todos, profissionais do ensino, refletir sobre as diversas experiências de formação que orientam nossas ações em sala de aula e, a partir dessa reflexão, possamos construir conhecimentos que tragam resultados positivos para o ensino de língua inglesa e para o nosso desenvolvimento profissional. 


\section{Referências}

AMARAL, M. J.; MOREIRA, M. A.; RIBEIRO, D. O papel do supervisor no desenvolvimento do professor reflexivo: estratégias de supervisão. In: ALARCÃO, I. (Ed.). Formação reflexiva de professores: estratégias de supervisão. Porto: Porto, 1996. p. 91-122.

BAILEY, K. M. et al. The language learner's autobiography: examining the "apprenticeship of observation". In: FREEMAN, D; RICHARDS, J. C. (Ed.). Teacher learning in language teaching. Cambridge: Cambridge University Press, 1996. p. 11-29.

GARCÍA, C. M. Formação de professores: para uma mudança educativa. Porto: Porto, 1999. 272 p.

GERALDI, C. G.; FIORENTINI, D.; PEREIRA, E. M. de A. (Ed.). Cartografias do trabalbo docente - professor(a) pesquisador(a). Campinas, SP: Mercado de Letras: Associação de Leitura do Brasil - ALB, 1998. 336 p.

LEFFA, V. J. Aspectos políticos da formação do professor de língua estrangeira. In: LEFFA, V. J. (Ed.). O professor de linguas estrangeiras: construindo a profissão. Pelotas: Educat, 2001. p. 333-355.

LITTLE, J. W.; McLAUGHLIN, M. (Ed.). Teacher's work. Individual, Colleagues and Contexts. Chicago: Teacher College Press, 1993.

MEDINA, A.; DOMINGUES, C. La formacion del profesorado en una sociedad tecnológica. Madrid: Cincel, 1989.

NÓVOA, A. et al. Vidas de professores. Porto: Porto Editora, 1995. 215 p.

NUNAN, D. Research Methods in Language Learning. New York: Cambridge University Press, 1992. 249 p.

SMYTH, J. Developing and sustaining critical reflection in teacher education. Journal of teacher education, v. 40, n. 2, p. 2-9, 1989.

SMYTH, J. Teacher's Work and the Politics of Reflection. American Educational Research Journal, v. 29, n.2, p. 267-300, 1992.

TARDIF, M. Saberesprofissionais dosprofessores e conbecimentos universitários. Elementos para uma epistemologia da prática profissional dos professores e suas conseqüências em relação à formação para o magistério. Rio de Janeiro: PUC-Rio, 1999. Mimeografado. 
TAVARES, J.; ALARCÃO, I. Psicologia do desenvolvimento e da aprendizagem. Coimbra: Almedina, 1992.

WALLACE, M. J. Trainning foreign language teachers: a reflective approach. Cambridge: Cambridge University Press, 1995. 180 p. 